\title{
ИССЛЕДОВАНИЕ ДИНАМИКИ РАЗВИТИЯ СЕКТОРА УСЛУГ В РЕГИОНАХ РФ С ПРОГНОЗОМ ДО 2024 ГОДА
}

\section{Болгов Алексей Юрьевич} Зотова Елизавета Юрьевна

студенты

Научный руководитель: Трещевский Юрий Игоревич

д.э.н., профессор

ФГБОУ ВО «Воронежский государственный университет»

\begin{abstract}
Аннотация: В статье приведены результаты исследования развития сектора услуг в регионах РФ, а также осуществлен прогноз дальнейшего развития выбранных показателей. Авторами проведен анализ абсолютных значений показателя оборота розничной торговли на душу населения в Республике Татарстан и Калужской области, рассмотрено их изменение в ретроспективе (2005-2019 гг.). Кроме того, выполнено трендовое прогнозирование показателя на период до 2024 года.
\end{abstract}

Ключевые слова: сфера услуг, сектор услуг, оборот розничной торговли, регион, прогноз, прогнозирование, динамика развития, тренд.

\section{STUDY OF THE DYNAMICS OF SERVICE SECTOR DEVELOPMENT IN THE RUSSIAN REGIONS WITH A FORECAST UNTIL 2024}

\section{Bolgov Aleksey Yuryevich Zotova Elizaveta Yuryevna}

Scientific adviser: Treschevsky Yuriy Igorevich

\begin{abstract}
: the article presents the results of the study of the development of the service sector in the regions of the Russian Federation, as well as the forecast of further development of selected indicators. The authors analyzed the absolute values of retail trade turnover per capita in the Republic of Tatarstan and the Kaluga Oblast and considered their change in the retrospective (2005-2019). In addition, the trend forecast of the indicator for the period up to 2024 was made.

Keywords: services, services sector, retail trade turnover, region, forecast, forecasting, development dynamics, trend.
\end{abstract}


В современной экономике Российской Федерации сектор услуг играет важную роль. Так, торговля (розничная и оптовая) из года в год становится крупнейшим по вкладу в ВВП страны сектором. Показатели, характеризующие оборот общественного питания, объём бытовых, транспортных, коммунальных услуг напрямую воздействуют на демографические процессы, происходящие в государстве, а также способствуют повышению социальной стабильности населения.

Сфера услуг РФ в последние 5-6 лет развивается высокими темпами. Однако стоит отметить, что развитие не происходит равномерно по всей территории страны - динамика находится в сильной зависимости от особенностей того или иного субъекта федерации. В этой связи проблема анализа и прогнозирования показателей, характеризующих сектор услуг, имеет существенное значение для стратегического развития регионов.

Значительный вклад в теоретические исследования регионального аспекта создания механизма регулирования территориального развития внесли А.Г. Гранберг, А.С. Маршалова, А.С. Новоселов [1, 2, 3] и другие ученые. Различные аспекты социально-экономического развития регионов, включая использование экономико-статистического анализа, на основании которого выявлены тенденции их развития, обоснованы прогнозы и предложены механизмы управления пространственными и функциональными подсистемами России, представлены в работах Е.А. Колесниченко [4], Т.А. Мясниковой [5], И.Е. Рисина [7], Н.В. Сироткиной [8], Ю. Трещевского, В. Эйтингона [9].

В настоящей статье сделана попытка проанализировать состояние сектора услуг Российской Федерации в разрезе отдельных регионов за период с 2005 до 2019 гг., а также сделать трендовый прогноз показателей на период до 2024 года.

Для расчетов нами использованы официальные статистические данные, полученные из 16 ежегодных статистических справочников «Регионы России. Социально-экономические показатели», размещенных на официальном сайте Федеральной службы государственной статистики (Росстата). Привести весь их список в статье небольшого объема не представляется возможным, в связи с этим в списке источников приведен последний из них [6].

Анализ проводился в динамике за 2005-2019 годы по ряду показателей, представленных в таблице 1. 
Таблица 1

\section{Основные показатели, характеризующие состояние сектора услуг РФ}

\begin{tabular}{|l|c|}
\hline \multicolumn{1}{|c|}{ Показатель } & Единица измерения \\
\hline Оборот розничной торговли на душу населения & руб. \\
\hline Оборот общественного питания на душу населения & руб. \\
\hline Объем бытовых услуг на душу населения & руб. \\
\hline Объем транспортных услуг на душу населения & руб. \\
\hline $\begin{array}{l}\text { Объем услуг связи / телекоммуникационных услуг на душу } \\
\text { населения }\end{array}$ & руб. \\
\hline Объем коммунальных услуг на душу населения & руб. \\
\hline
\end{tabular}

На начальном этапе исследования по данным показателям был проведен виртуальный кластерный анализ 77 регионов страны с использованием программ MSExcel и Статистика 10.1, с помощью которых произошло разбиение регионов на 5 кластеров («А», «Б», «В», «Г», «Д»). В исследование не включались регионы, по которым отсутствовали данные в официальной статистике за рассматриваемый период, а также регионы, которые при первичной кластеризации сформировали отдельный кластер-лидер, значения показателей в котором были намного выше значений в других кластерах, что приводило к сильным искажениям в исследовании.

Расчеты произведены по данным за 2005 и 2019 годы.

Далее представлен анализ только для кластеров «Б» и «В», так как они являются явными лидерами в анализируемой сфере деятельности.

Состав кластера «Б» представлен в таблице 2.

Таблица 2

\section{Состав кластера Б за исследуемый период}

\begin{tabular}{|l|l|}
\hline 2005 & 2019 \\
\hline Республика Башкортостан & Московская область \\
\hline Республика Татарстан & Краснодарский край \\
\hline Краснодарский край & Ростовская область \\
\hline Красноярский край & Республика Татарстан \\
\hline Пермский край & Свердловская область \\
\hline Приморский край & Тюменская область (вместе с АО) \\
\hline Иркутская область & \\
\hline Кемеровская область & \\
\hline Московская область & \\
\hline Новосибирская область & \\
\hline Ростовская область & \\
\hline Самарская область & \\
\hline Свердловская область & \\
\hline Томская область & \\
\hline Челябинская область & \\
\hline
\end{tabular}


В кластере «Б» в 2005 и 2019 г. модельным регионом является Республика Татарстан, занимающая ближайшее к виртуальному центру кластера положение по сумме средних нормированных значений [10].

Состав кластера «В» представлен в таблице 3.

Таблица 3

Состав кластера В за исследуемый период

\begin{tabular}{|l|l|}
\hline \multicolumn{1}{|c|}{2005} & \multicolumn{1}{|c|}{2019} \\
\hline Республика Карелия & Белгородская область \\
\hline Ставропольский край & Воронежская область \\
\hline Архангельская область (вместе с АО) & Калужская область \\
\hline Белгородская область & Липцкая область \\
\hline Брянская область & Ярославская область \\
\hline Владимирская область & Республика Карелия \\
\hline Волгоградская область & Республика Коми \\
\hline Вологодская область & Архангельская область (вместе с АО) \\
\hline Воронежская область & Вологодская область \\
\hline Ивановская область & Калининградская область \\
\hline Калининградская область & Мурманская область \\
\hline Калужская область & Республика Башкортостан \\
\hline Курская область & Пермский край \\
\hline Ленинградская область & Нижегородская область \\
\hline Липецкая область & Самарская область \\
\hline Нижегородская область & Челябинская область \\
\hline Новгородская область & Красноярский край \\
\hline Омская область & Иркутская область \\
\hline Орловская область & Новосибирская область \\
\hline Пензенская область & Омская область \\
\hline Псковская область & Томская область \\
\hline Рязанская область & Приморский край \\
\hline Саратовская область & Амурская область \\
\hline Смоленская область & \\
\hline Тамбовская область & \\
\hline Тверская область & \\
\hline Тульская область & \\
\hline Ульяновская область & \\
\hline Ярославская область & \\
\hline
\end{tabular}

В кластере «В» в 2005 г. и 2019 г. модельным регионом является Калужская область, занимая ближайшее к виртуальному центру кластера положение по сумме средних нормированных значений [10].

Нами были проанализированы следующие шесть показателей по каждому кластеру:

1. Оборот розничной торговли на душу населения, руб.

2. Оборот общественного питания на душу населения, руб.

3. Объём бытовых услуг на душу населения, руб.

4. Объем транспортных услуг на душу населения, руб. 
5. Объем телекоммуникационных услуг на душу населения, руб.

6. Объем коммунальных услуг на душу населения, руб.

Для представления в исследовании был отобран показатель «оборот розничной торговли на душу населения», так как по нему наблюдалась наибольшая степень корреляции данных по всем пяти кластерам.

В качестве предполагаемых функций использованы линейная, логарифмическая (по натуральному логарифму), полиномиальная.

Результаты показателя «оборот розничной торговли на душу населения» в Республике Татарстан представлены на рисунке 1.

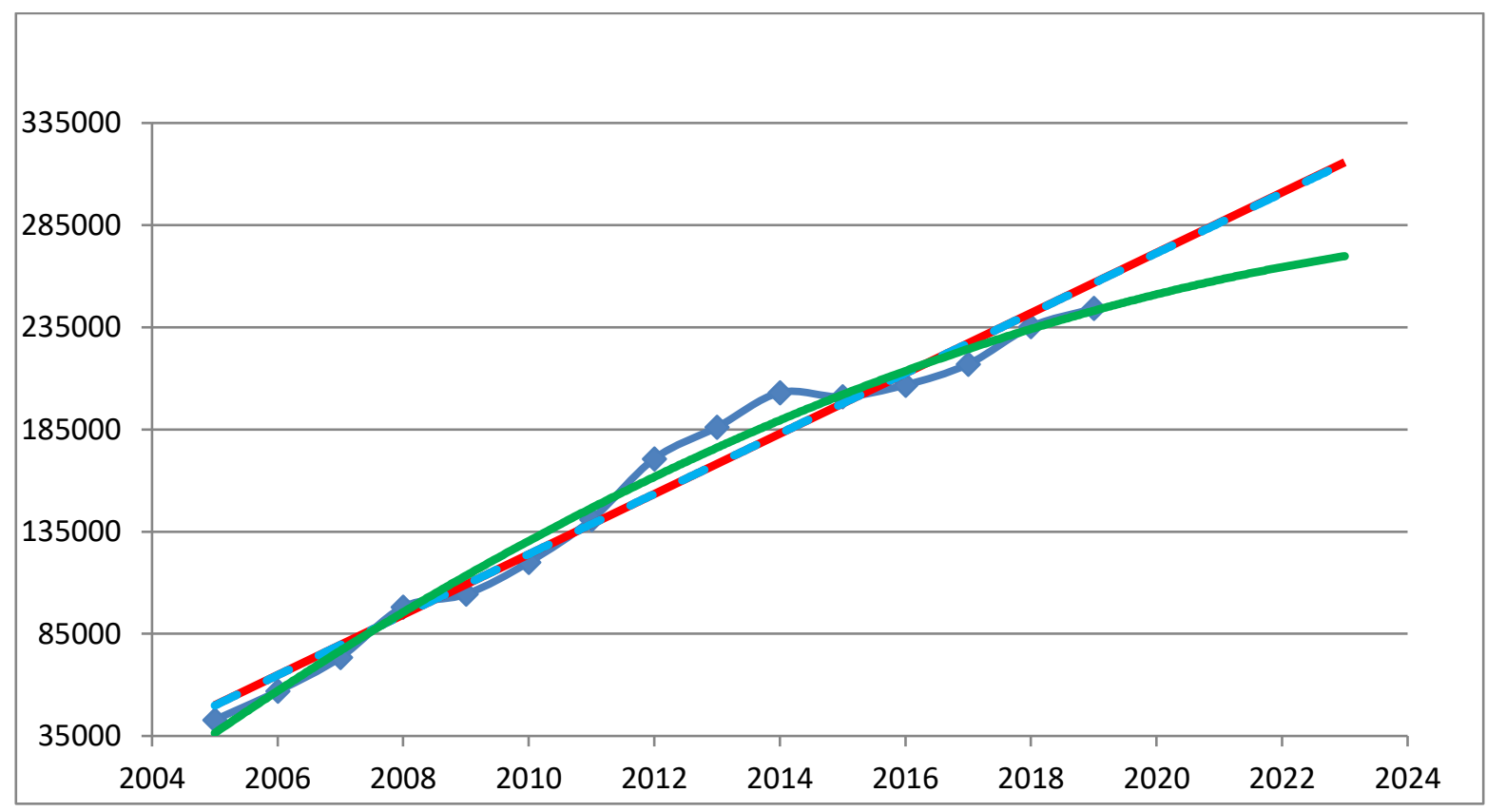

Рис. 1. Оборот розничной торговли на душу населения, руб.

В таблице 4 приведены основные обозначения рисунка 1.

Таблица 4

Обозначения рисунка 1

\begin{tabular}{|l|l|}
\hline Основной график & \\
\hline Линейная функция & $\begin{array}{l}\mathrm{y}=14762,1 \mathrm{x}-29547941,9 \\
\mathrm{R}^{2}=0,9747\end{array}$ \\
\hline Логарифмическая функция & $\begin{array}{l}\mathrm{y}=29704531,2 \ln (\mathrm{x})-225805481,5 \\
\mathrm{R}^{2}=0,9749\end{array}$ \\
\hline Полиномиальная функция & $\begin{array}{l}\mathrm{y}=-449,4 \mathrm{x}^{2}+1823046,8 \mathrm{x}-1848673936,5 \\
\mathrm{R}^{2}=0,9880\end{array}$ \\
\hline
\end{tabular}


где $\mathrm{x}$ - i-год в периоде исследования;

у - значение показателя в і-году в руб.;

$\mathrm{R}^{2}$ - коэффициент детерминации.

В целом по данному показателю у отобранного нами представителя кластера «Б» в исследуемом периоде прослеживается тенденция роста, за исключением небольшого «провала» оборота розничной торговли с 2014 по 2016 гг. Средний темп роста с 2005 по 2019 гг. составил 113,74\%, максимальные темп роста наблюдается с 2006 по 2008 гг. - более 130\%; минимальный темп роста наблюдается в 2015 году - 99\%. Полученные показатели говорят о планомерном развитии сферы розничной торговли в Республике Татарстан в исследуемом периоде.

На основании официальных статистических данных спрогнозируем значение показателя на 5 лет вперед по линейной, логарифмической и полиномиальной функциям. Данные прогнозирования представлены в таблице 5.

Таблица 5

Прогноз показателя «оборот розничной торговли на душу населения, руб.» по республике Татарстан

\begin{tabular}{|c|c|c|c|}
\hline Год/Функция & Линейная & Логарифмическая & Полиномиальная \\
\hline 2020 & 271485,7 & 271332,7 & 251114,0 \\
\hline 2021 & 286247,8 & 286034,3 & 258236,7 \\
\hline 2022 & 301009,9 & 300728,6 & 264460,7 \\
\hline 2023 & 315772,0 & 315415,6 & 269785,9 \\
\hline 2024 & 330534,0 & 330095,4 & 274212,4 \\
\hline
\end{tabular}

В анализируемом периоде прогнозируется устойчивый рост по всем трем функциям. Наиболее оптимистичный прогноз прослеживается по линейной функции: средний темп роста составляет 105,02\%; наименее оптимистичный по полиномиальной функции: средний темп роста составляет 102,23\%.

Результаты показателя «оборот розничной торговли на душу населения» в Калужской области представлены на рисунке 2. 


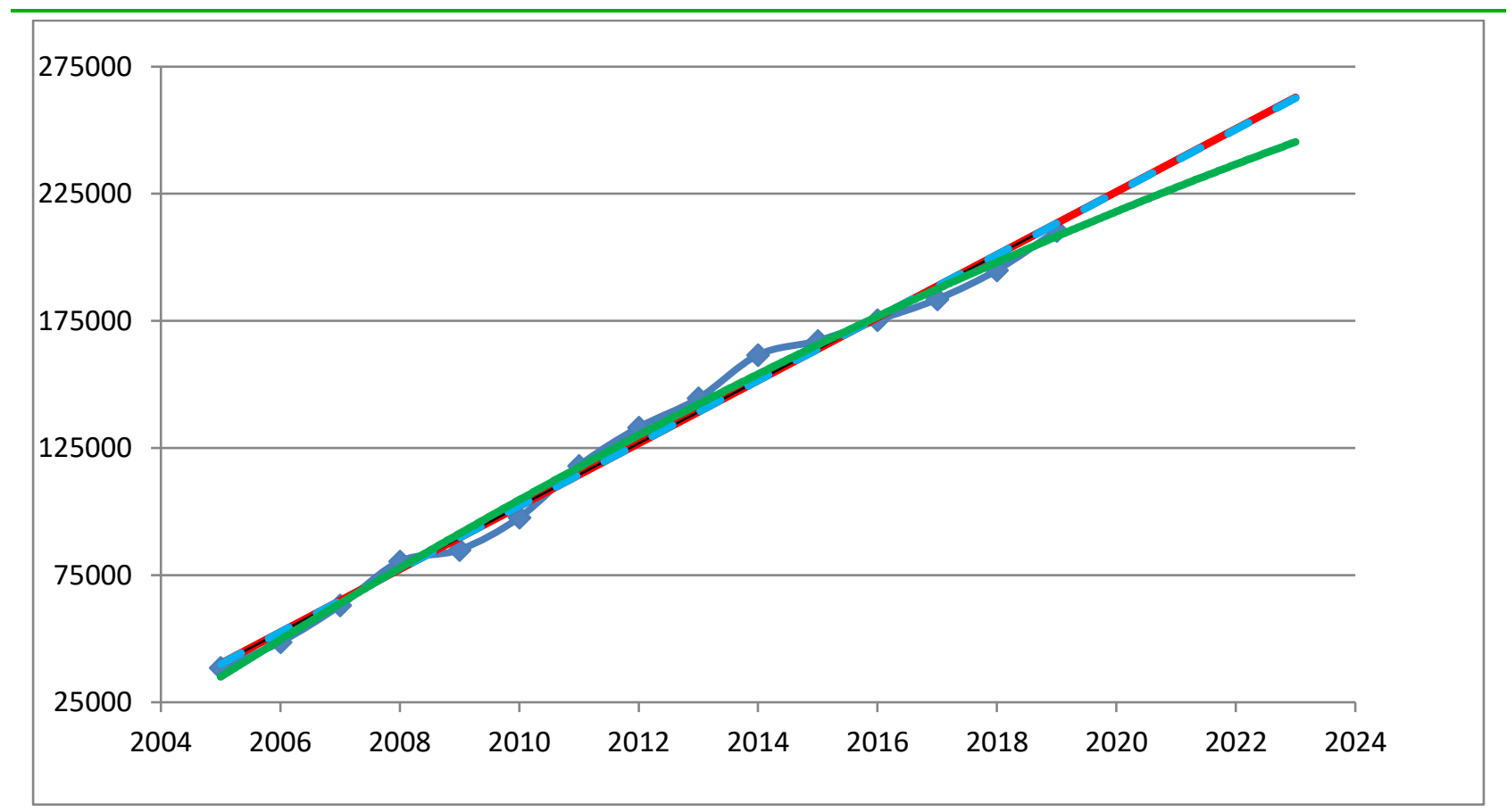

Рис. 2. Оборот розничной торговли на душу населения, руб.

В таблице 6 приведены основные обозначения рисунка 2.

Таблица 6

Обозначения рисунка 2

\begin{tabular}{|l|l|}
\hline Основной график & \\
\hline Линейная функция & $\begin{array}{l}\mathrm{y}=12372,0 \mathrm{x}-24765712,9 \\
\mathrm{R}^{2}=0,9922\end{array}$ \\
\hline Логарифмическая функция & $\begin{array}{l}\mathrm{y}=24893691,5 \ln (\mathrm{x})-189236570,6 \\
\mathrm{R}^{2}=0,9923\end{array}$ \\
\hline Полиномиальная функция & $\begin{array}{l}\mathrm{y}=-171,3 \mathrm{x}^{2}+701634,2 \mathrm{x}-718160256,7 \\
\mathrm{R}^{2}=0,9950\end{array}$ \\
\hline
\end{tabular}

где $\mathrm{x}$ - i-год в периоде исследования;

у - значение показателя в і-году в руб.;

$\mathrm{R}^{2}$ - коэффициент детерминации.

По описанному выше показателю у отобранного нами представителя кластера «В» в исследуемом периоде прослеживается тенденция роста. Средний темп роста с 2005 по 2019 гг. составил 113,22\%, максимальный темп роста наблюдается с 2006 по 2008 гг. - в среднем 127,72\%; минимальный темп роста наблюдается в 2017 году - 104,71\%. Полученные показатели говорят об 
устойчивом развитии сферы розничной торговле в Калужской области в исследуемом периоде.

На основании официальных статистических данных спрогнозируем значение показателя на 5 лет вперед по линейной, логарифмической и полиномиальной функциям. Данные прогнозирования представлены в таблице 7.

Таблица 7 Прогноз показателя «оборот розничной торговли на душу населения, руб.» по Калужской области

\begin{tabular}{|l|l|l|l|}
\hline Год/Функция & Линейная & Логарифмическая & Полиномиальная \\
\hline 2020 & 225784,8 & 225650,5 & 218019,7 \\
\hline 2021 & 238156,8 & 237971,1 & 227479,9 \\
\hline 2022 & 250528,8 & 250285,6 & 236597,4 \\
\hline 2023 & 262900,8 & 262594 & 245372,4 \\
\hline 2024 & 275272,9 & 274896,2 & 253804,8 \\
\hline
\end{tabular}

В прогнозируемом периоде наблюдается устойчивый рост по всем трем функциям. Наиболее оптимистичен прогноз по линейной функции: средний темп роста составляет $105,08 \%$; наименее оптимистичный - по полиномиальной функции: средний темп роста составляет 103,87\%.

Таким образом, анализ динамики оборота розничной торговли на душу населения как одного из показателей, характеризующих состояние сферы услуг модельных регионов кластеров «Б» и «В», дает основание утверждать, что она развивается высокими темпами. Проведенный трендовый анализ позволяет прогнозировать рост значений показателя в будущем. Все это говорит о динамичном развитии сектора услуг в регионах РФ.

\section{Список литературы}

1. Гранберг А. Г. Основы региональной экономики: учебник / А. Г. Гранберг - М.: ГУ ВШЭ, 2004. -495 с.

2. Маршалова А. С. Конкурентоспособность и стратегия развития муниципальных образований / А. С. Маршалова, А. С. Новоселов // Регион: экономика и социология. - 2010. - № 3. - С. 219-236.

3. Гранберг А. Г. Моделирование пространственного развития экономики России / А. Г. Гранберг // Стратегическое планирование в регионах и городах 
России. Доклады участников VII Общероссийского форума лидеров стратегического планирования. - СПб.: Леонтьевский центр, 2009. - С. 32-34.

4. Колесниченко Е. А. Направления снижения дифференциации регионального развития / Е. А. Колесниченко // Социально-экономические явления и процессы. - 2009. - № 1(13). - С. 58-63.

5. Мясникова Т. А. Стратегирование социально - экономического развития муниципальных образований в регионах России: теория, методология, методическое обеспечение: монография / Т.А. Мясникова. - Воронеж : Издательско-полиграфический центр «Научная книга», 2015. - 271 с.

6. Регионы России. Социально-экономические показатели. 2020: Р32 Стат. сб. / Росстат. - М., 2020. - С. 895-896, 912-913, 944-945, 948-949, 952-953, 956-957.

7. Рисин И. Е. Региональная кластерная политика: концептуальное, методическое и инструментальное обеспечение / И. Е. Рисин, Ю. И. Трещевский. М.: Русайнс, 2015. - 168 с.

8. Сироткина Н. В. Научно-производственные кластеры: теория и практика управления российскими регионами : монография / Н. В.Сироткина, Ю. А. Ахенбах. - Воронеж, Издательско-полиграфический центр «Научная книга», 2012. $-533 \mathrm{c}$.

9. Трещевский Ю. И. Генезис и развитие концепций реактивного управления системами в условиях организационно-экономических инноваций / Ю.И. Трещевский, В.Н. Эйтингон, Д. Ю. Трещевский // Вестник Воронежского государственного университета. Серия: Экономика и управление. - 2014. - № 1. - C. 120-131.

10. Трещевский Ю. И. Динамика эколого-экономической активности российских регионов - сравнительный анализ / Ю. И. Трещевский, В. А. Новиков, А. Г. Малугина // Современная экономика: проблемы и решения. 2020. № 8 (128). C. 137-148.

(C) А.Ю. Болгов, Е.Ю. Зотова, 2021 